\title{
On the Relationship between the Overcoming of the Inter-Language and the Language Input for the Russian Learners
}

\author{
Yan LIU \\ College of Foreign languages of Tianjin Polytechnic University, Tianjin, China \\ Email:liuyan@tjpu.edu.cn
}

Key words: Russian learners, inter-language, language input

\begin{abstract}
As the Russian learners, the plentiful language input which is correct and understandable plays a significant role in the overcoming of the inter-language. The Russian teachers should put emphasis on this kind of input and investigate the details in the teaching of the listening and reading. These strategies should be applied into practice, which will help the learners shorten the process of overcoming the inter-language and master Russian as soon as possible.
\end{abstract}

\section{Introduction}

When using Russian, Russian learners often make mistakes. This problem is confusing and frustrating. Thus, it is very urgent for teachers to help students to overcome difficulties and output correctly.

The mistakes made in the Russian learning are not just about the language, but the inner language system. This said system is in the intermediate state, between Chinese and Russian in the structure. In other words, the language is not the direct translation of the mother tongue and it's not consistent with the target language, either. This is the inter-language, put forward by Larry Selinker. Russian learners obey certain rules in using the inter-language instead of using it in a random way. This system is a changing continuum. Moreover, as new language rules are taken in, it will be overcome and the mistakes will be corrected, too. Then the learners will master the right Russian form gradually.

As the saying goes, "There is no smoke without fire." Everything happens for a reason. So how does the inter-language occur? Through the study and systematically analysis, we know that it has the following reasons at least --- transferring of the mother tongue, generalization of the target language rules, wrong use of the communicative strategies and learning strategies, and so on. With regard to these aspects, what should Russian teachers do to help students overcome and get rid of the bothering inter-language? The author of tries to give a few suggestions from the

Perspective of the language input in class. It is hoped that this paper can provide a manageable and controllable key to unlock the lock in the Russian learning, so as to overcome the inter-language and shorten the process ofinter- language using.

\section{The Relation between Plentiful Correct Comprehensible Language Input And Inter- Language Overcoming}

Plentiful correct and comprehensible language input plays a vital role in the overcoming of inter-language. According to the second language acquisition theory, we find that the Russian acquisition is a process in which language (Russian) input formulates the language internal mechanisms ---- language output ${ }^{[1]}$. The input of language is the basis of language output, without which language output is just like the water without source or the tree without a root. The quantity and quality of language input determine that of language output. Therefore a good control of language input in Russian teaching will overcome Russian learners' inter-language effectively and shorten their process of language.

Correctness is the most basic requirement of language input, and the primary condition of Russian learners to overcome inter-language and shorten their process of inter-language. Learners are supposed to produce correct language output only by correct language input. Teachers and 
teaching materials are major channels to supply language output, the correctness of knowledge given by them is essential to the success of teaching. Besides, teachers' language knowledge, Russian level and the contents of teaching materials will provide a demonstration effect to Russian learners. Supposing Russian teachers with insufficient knowledge, invalid foundations, nonstandard pronunciation and low teaching quality, then what kind of consequences will be brought by them? The learners will receive incorrect language knowledge by listening or reading in such kind of Russian teaching process. They will imitate the pronunciation of teachers and learn inauthentic language, which is so absurd, not to mention the overcoming of inter-language! Therefore, the correct language input is very important.

Plentiful of language input is the guarantee of a fluent language output and inter-language overcoming, which can also endow Russian learners with a full language perception consisting of phonetics, vocabularies, grammatical rules and semantics in Russian. It is essential for Russian learners to comprehend and communicate in Russian correctly. As has been previously mentioned, the negative transfer of mother tongue, the generation of Russian rules and interference in culture are all concerned with learners' inadequate correct language input and their failure to form a perception towards Russian fully and comprehensively.

Much language input needs to get rid of meaningless drills which have been used in the same language material and applied in Russian language teaching repeatedly, so it requires large amounts of language input information. Providing many new language materials for learners will constantly make them interested and motivated in the materials presented to them under the simulation of new information. If learners are eager to get new more Russian information, they will have active minds and further obtain more Russian knowledge effectively.

Comprehensible language input is the pivot of language input. Not only with a feature of being comprehensible, but also quantities of appropriate language input are necessary in the process of Russian language input, which also involves the difficulty and quality of language input. The distinguished American psychologist Stephen Krashen once said: "even if the second language learners have a proper context and much incomprehensible language input, they will lose confidence and regard these as a waste of time., ${ }^{[2]}$ He suggests that the best way to teach a second language is to give learners a comprehensive language input, which matches the learners' present level. Krashen proposed a comprehensible input mode as $i+1$,irefers to learners' present level, and $i+1$ means that learners can reach a higher level on the basis of present level. Therefore, this language input could get learners to understand and figure out what it is meanwhile it can facilitate learner's language level. Much comprehensible language input may lead Russian learners to absorb and internalize this into forming one's own knowledge structure, thus forming an overall perception, reducing language errors eventually, overcoming inter-language and finally shortening this period of inter-language for Russian language learners.

\section{The Way of Much Appropriate Comprehensible Language Input}

It is widely known that listening, speaking, reading, and writing are the main ways for human communication. Among these, listening and reading belong to the process of language input while speaking and writing belong to the process of language output. Russian learners just make use of listening and reading to absorb language information, internalize language input into one's own language structure, then express ideas and transmit messages in the process of speaking and writing, so listening and reading - the approach for learners to obtain language input. In the process of Russian learning, much appropriate comprehensible language input can be facilitated by means of the teaching of listening and reading.

\section{Listening}

To select the appropriate listening materials, the following aspects should be taken into account: firstly, the language material, no matter what topic it is, it should be true and have the communicative meaning. You'd better use the native speakers' records (of different age, identity and gender) in natural situations. In the Russian class, the Chinese teachers should try to 
minimize artificial ingredients and keep the material what it is; secondly, intelligibility. As for listening, the difficulty and speed must be appropriate, following the principle of step by step, on the premise that learners can understand the basic content. Third, materials must be appealing. If you want to get as much input as possible, you need to listen. It is obvious that the appealing listening material attracts the listeners to spend more time in listening. The appealing of the listening material is the crucial factor which may arouse the listeners' interest ${ }^{[3]}$. In the teaching of Russian, the listening material chosen should be based on the age and cognitive characteristics of the learner and it also should be close to their life and have the realistic meaning which may trigger their interest.

\section{Reading}

Reading is an important way of language input which always catches the attention in the field of foreign language teaching. "Read widely, and you will wisely write.” this old saying illustrates the importance of reading.

\section{The Combination of Intensive Reading and Extensive Reading.}

In the teaching of Russian, teachers have attached great importance to the analysis teaching, namely the intensive reading. In the class, the teaching of Russian usually relates to the intensive reading, and teachers spend a lot of time on the review to master language knowledge, thus the special training of reading is not enough. And the quantity and the length of the text are also far from the guarantee provided by the amount of reading materials ${ }^{[4]}$. On the other hand, because the text contains a large number of knowledge points (new words and new language structure, etc.), learners cannot read smoothly. So on intensive reading class, learners can only obtain the very limited amount of language input. In the teaching of Russian, the Russian teacher should wildly expand the reading channels to consolidate and expand vocabulary and language knowledge, and increase the learner 's language input. Reading becomes a beneficial supplement of intensive reading in this area. Extensive reading teaching should be regularized and curriculum, including providing specific reading textbooks, scientific course arrangement, the provision of the target of teaching etc. Combining intensive reading and extensive reading, thus ensure the Russian learner's language input.

\section{Rational Selection of Reading Materials}

Reading and listening are both the inputs of language. Attention should be paid to the authenticity and intelligibility of the language, university of subjects and knowledge and interest when selecting the reading material (especially extensive reading). Authenticity guarantees the correctness of language input, intelligibility decides quality and effect of the language input, university of subjects, knowledge and interest are strongly related to the speed and quantity of reading.

Reading materials should be based on the contemporary written language when teachers select, as far as possible, the Russian works. The reading materials should contain certain knowledge and the connotation of Russian culture. It should not exceed the learner's background knowledge, choosing materials which attract learners. Such as International current affairs, Internet, sports, art, human and nature (environmental protection) ${ }^{[5]}$.

Thus, correct, large and comprehensible language input plays a crucial role in overcoming inter-language for learners of Russian language. Russian teachers should pay attention to the correct, large, comprehensible language input in the teaching process. The teachers should investigate in the listening and reading details, put these teaching strategies into practice, help Russian learners to shorten the time of learning inter-language and overcome the inter-language problems and enable them to master standard and fluent Russian as soon as possible. 


\section{References}

[1] Xu Yu long. The introduction to the comparative linguistics [M], Shanghai Foreign language Education Press,1997, p102

[2] Lv Bi song, The Development Outline of the Teaching of Chinese as a foreign language Language \& Culture Press,1990,p223

[3] Zhu Chun.The Psychology of foreign language teaching[M],Shanghai Foreign language Education Press, 1997,p35

[4]Department of Psychology of East China Normal University, The Psychology,East China Normal University Press,p87

[5]Huang, Xunjing, Dictionary of New Word New Senses in Russian Loanwords [Z], Beijing: World Publishing Corporation, 2000,p89 